ARTIGO

Recebido em:

28/04/2017

Aceito em: 09/04/2018

\title{
A construção de um plano de classificação arquivístico colaborando com a inovação incremental
}

\author{
The construction of a filing plan as part of incremental innovation
}

Evelin MINTEGUI (eminteguimail@gmail.com $)^{*}$
Bruna dos Santos ÁVILA ( $\underline{\text { avilabru95@gmail.com }})^{* *}$
Cezar KARPINSKI (cezar.karpinski@gmail.com $)^{* * *}$
* Doutoranda do Programa de Pós-Graduação da Universidade Federal de Santa Catarina (PGCIN-
UFSC). Professora do Curso de Arquivologia da Universidade Federal do Rio Grande (FURG).
** Arquivista graduada pela Universidade Federal do Rio Grande (FURG).
*** Professor do Departamento de Ciência da Informação da Universidade Federal de Santa Catarina e
de seu Programa de Pós-Graduação em Ciência da Informação (PGCIN-UFSC).

\section{Resumo}

Este trabalho trata da construção do plano de classificação de documentos de arquivo em uma entidade, utilizando a metodologia de identificação arquivística. Os resultados do levantamento de tipologias produzidas subsidiaram a criação de um plano de classificação funcional e possibilitaram a detecção de processos não normatizados, bem como algumas discrepâncias entre a produção de documentos normatizada e a real. Considera-se que a metodologia contribuiu com a inovação incremental, uma vez que está se caracteriza por melhoramentos a produtos /processos já existentes.

Palavras-chave: Organização do Conhecimento. Plano de Classificação. Identificação Arquivística. Inovação.

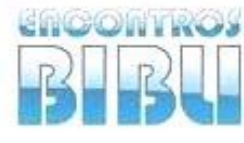

v. 23, n. esp., 2018 p. $16-24$

ISSN 1518-2924

\section{Abstract}

This work deals with the construction of the classification plan of archival documents in an entity, using the methodology of archival identification. The results of the survey of typologies produced subsidized the creation of a functional filing plan and enabled the detection of non-standardized processes, as well as some discrepancies between the production of normative documents and the actual one. The methodology is considered to have contributed to incremental innovation since it is characterized by improvements to existing products/processes.

Keywords: Knowledge Organization. Filing Plan. Archives Identification. Innovation.

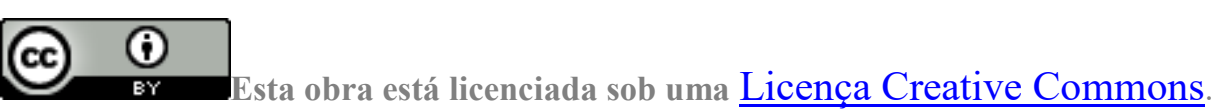




\section{INTRODUÇÃO}

Este artigo tem objetivo de demonstrar o processo de construção de um plano de classificação para o Órgão de Gestão de Mão-de-Obra do Trabalho Portuário Avulso do Porto Organizado do Rio Grande - OGMO/Rio Grande, e sua relação com a inovação incremental. O OGMO/Rio Grande é uma entidade constituída nos termos da Lei n.. 8.630/93, sob a forma de associação civil, têm como finalidade a administração do fornecimento de mão-de-obra do trabalhador portuário.

0 acervo é utilizado diariamente pelos colaboradores da empresa e contém informações sobre os mais de mil trabalhadores do Porto de Rio Grande, distribuídos entre trabalhadores portuários, trabalhadores portuários avulsos que contemplam as categorias de capatazia, estiva, conferência de carga e vigilância de embarcações, assim como os sindicatos, tomadores de serviços e operadores portuários. 0 arquivo do OGMO/Rio Grande também costuma receber solicitações do público externo, incluindose trabalhadores inativos e outros membros da comunidade interessados em seu acervo.

Dessa forma, houve uma grande demanda por parte da instituição em relação à organização do arquivo, já que o órgão não possuía nenhum programa formal de gestão documental. Além disso, o acervo apresenta um grande potencial de pesquisa, especialmente em relação a dados sobre a história do trabalho portuário organizado da cidade de Rio Grande, uma vez que a atividade portuária tem grande impacto na economia local.

A primeira iniciativa em relação à organização do acervo foi a concepção de um plano de classificação arquivístico. Embora não existisse um programa formalizado de gestão de documentos no órgão, o diagnóstico arquivístico constatou a existência de um programa de qualidade e produtividade (SGQ), implementado por um setor específico de controle de qualidade. À partir de então foram traçadas algumas estratégias para a construção do instrumento de gestão documental, considerando o contexto do OGMO/Rio Grande.

Nesse contexto, coloca-se que a criação de um plano de classificação pode ser considerada como uma inovação de tipo organizacional e nível incremental. A seguir, apresentam-se as ideias e tipologias de inovação.

\section{A INOVAÇÃO E SUAS TIPOLOGIAS}

A inovação é um conceito muitas vezes difundido como sinônimo de invenção ou associado a uma novidade tecnológica. De acordo com Capuano (2015), em estudo que levanta fontes de informação sobre o tema, o conceito de inovação é polissêmico, fundamentado em diversos campos teóricos, desde a administração de negócios, engenharia de produção, biologia evolutiva e psicologia cognitiva. 0 autor ainda aponta que o conceito pode ser tratado desde os níveis de contas nacionais, melhor desenvolvido pelas ciências econômicas, até o nível de empresas, por sua vez, melhor abordado pela área de administração de negócios.

Ainda segundo Capuano (2015), um dos principais autores que introduzem o tema da inovação seria Shumpeter, que colocava a inovação de maneira a desprendê-la da abordagem de invenção tecnológica, que limita sua compreensão mais ampla. Shumpeter diferenciava inovação de invenção e definia que a inovação não seria simplesmente a criação de uma nova coisa, mas sim a devida alteração em um processo de produção ou organização, ou na abertura de novos mercados ou fontes de suprimentos - uma alteração concreta.

Com o estabelecimento de uma preocupação internacional, e especialmente 
procurando dar conta de representações que permitissem o uso de comparações estatísticas, surge o Manual de Oslo, criado pela Organização para Cooperação e Desenvolvimento Econômico (OCDE) ${ }^{1}$. Ele é voltado para identificar inovações em empresas privadas. A novidade do escopo desta última edição é que, embora focado em inovações tecnológicas de produtos e processos, diretrizes e faz notar outros tipos de inovação, sobretudo as inovações organizacionais. Define, então, inovação como algo que é novo, não necessariamente inédito, para a empresa que a introduz em seus negócios.

O Manual traz, ainda definições sobre o grau de novidade e difusão de uma inovação, que pode ser nova para a empresa, para o mercado ou para o mundo. Para que possamos compreender o escopo da inovação no Manual de Oslo, seguem as definições de suas tipologias: inovações de processo, inovações organizacionais e inovações de marketing.

Inovações de produto envolvem mudanças significativas nas potencialidades de produtos e serviços. Incluem-se bens e serviços totalmente novos e aperfeiçoamentos importantes para produtos existentes. Inovações de processo representam mudanças significativas nos métodos de produção e de distribuição.

As inovações organizacionais referem-se à implementação de novos métodos organizacionais, tais como mudanças em práticas de negócios, na organização do local de trabalho ou nas relações externas da empresa. As inovações de marketing envolvem a implementação de novos métodos de marketing, incluindo mudanças no design do produto e na embalagem, na promoção do produto e sua colocação, e em métodos de estabelecimento de preços de bens e de serviços (OCDE, 2016, p. 23).

As inovações organizacionais e de marketing também são conhecidas como inovações não-técnicas ou não-tecnológicas (DAMANPOUR, 2017). A OCDE (2016) coloca que embora as inovações organizacional e de marketing fossem compreendidas como algo provocado pela inovação de produto e mercado, as primeiras poderiam ser, na verdade, a razão de desenvolvimento das últimas. Por isso, foram reconhecidas na última edição do Manual.

Neste trabalho gostaríamos de destacar a inovação organizacional. De acordo com a OCDE (2006), a inovação organizacional não seria apenas parte do apoio a inovações de produto e processos, elas contribuíram para a melhoria da qualidade, da eficiência do trabalho, da troca de informações, bem como no aprendizado de tecnologias e circulação do conhecimento. Desta maneira, as disciplinas do campo da informação e do tratamento dos documentos podem contribuir com os processos de inovação organizacional de maneira especial, uma vez que tem como objetivo

\footnotetext{
${ }^{1}$ De acordo com o Manual de Oslo, a "OECD é um fórum único no qual os governos de 30 democracias trabalham juntos para endereçar os desafios econômicos, sociais e ambientais da globalização. A OECD também está na vanguarda dos esforços para compreender e ajudar os governos a responder a novos desenvolvimentos e inquietações, como a governança corporativa, a economia da informação e os desafios de uma população que envelhece. A Organização provê um ambiente no qual os governos podem comparar experiências de políticas, buscar respostas para problemas comuns, identificar boas práticas e trabalhar para coordenar políticas domésticas e internacionais". Os membros da OECD são: Austrália, Áustria, Bélgica, Canadá, República Tcheca, Dinamarca, Finlândia, França, Alemanha, Grécia, Hungria, Islândia, Irlanda, Itália, Japão, Coréia, Luxemburgo, México, Países Baixos, Nova Zelândia, Noruega, Polônia, Portugal, República Eslovaca, Espanha, Suécia, Suíça, Turquia, Reino Unido e Estados Unidos.
} 
justamente agir para a otimização da produção e uso da informação, preocupadas tanto com seus registros (documentos) quanto com seus fluxos.

A OCDE (2006) empreende seus esforços na padronização de conceitos para permitir a aferição de indicadores de inovação em empresas, ainda que reconhecendo que a inovação possa acontecer em qualquer setor e tipo de mercado. Entretanto, de acordo com revisão realizada por Damaunpour (2017), a inovação organizacional é um termo que tem acompanhado diversos estudos, incluindo tanto organizações públicas como privadas, em diversos níveis. Outro ponto de contato do campo da informação com a inovação organizacional tem sido o conceito de memória. A memória organizacional tem sido apontada como fator para vantagem competitiva (CAMISÓN; VILLAR LOPEZ, 2011), bem como condicionante para o aprendizado relacional, que por sua vez, promove a inovação (FANG et. al., 2011). Citamos, ainda, estudo que demonstra o potencial da memória organizacional na criação de valor (LEE et. al., 2011).

Outra característica da inovação é seu grau de impacto. Para Tironi e Cruz (2008) inovação seria radical, ou seja, caracterizada como algo que sendo novidade tecnológica ou mercadológica, levaria à criação de um novo mercado, podendo (ou não) acarretar a descontinuidade do mercado existente (disruptiva). Inovação incremental, por sua vez, poderia ser definida como aquela que incorpora melhoramentos (características técnicas, utilizações, custos) a produtos e processos preexistentes.

Complementando o conceito de inovação incremental, cita-se Lemos, que coloca que

As inovações podem ser ainda de caráter incremental, referindo-se à introdução de qualquer tipo de melhoria em um produto, processo ou organização da produção dentro de uma empresa, sem alteração na estrutura industrial (Freeman, 1988). Inúmeros são os exemplos de inovações incrementais, muitas delas imperceptíveis para o consumidor, podendo gerar crescimento da eficiência técnica, aumento da produtividade, redução de custos, aumento de qualidade e mudanças que possibilitem a ampliação das aplicações de um produto ou processo (LEMOS, 1999, p. 124).

A seguir, apresenta-se definições e o processo de construção de um plano de classificação arquivístico para que possamos refletir sobre suas possibilidades enquanto inovação organizacional incremental.

\section{PLANOS DE CLASSIFICAÇÃO ARQUIVÍSTICOS}

A organização dos documentos de arquivo depende da criação de um instrumento de classificação que possa nortear todas as demais intervenções arquivísticas. Por isso, a classificação é citada como função matricial do fazer arquivístico (SOUSA, 2008). A classificação permite que se conheça toda a organização produtora de documentos, permitindo que se determine o contexto de produção de cada tipo documental. Dessa maneira ela refletirá nas outras fases do tratamento arquivístico².

Para a criação de um instrumento de classificação - o plano de classificação, é necessário definir os limites do fundo documental a ser classificado. 0 universo de ação para conjuntos documentais, desta forma, deve seguir o princípio da proveniência, que, de acordo com Rousseau e Couture (1998, p. 83-84,) apresenta dois graus. Em seu

\footnotetext{
2 De acordo com Rousseau e Couture (1998) as funções arquivísticas são produção, classificação, avaliação, descrição, difusão, preservação e aquisição.
} 
primeiro grau, o princípio consiste em manter como uma unidade lógica os documentos de uma mesma entidade, pessoa ou família. Em seu segundo grau, o princípio defende que a ordem original deva ser mantida. Tal 'ordem original' corresponde à organização interna do fundo, que longe de querer dizer que a disposição originalmente dada à determinados documentos deva ser mantida, propõe que seja desenvolvida uma organização que seja fiel ao modo de produção dos documentos de uma entidade.

Isso significa que não devem ser utilizadas classificações existentes para outros fins, como aquelas construídas para documentos biblioteconômicos, por exemplo, em documentos de arquivo. É necessário que se conheça a entidade produtora de forma a conseguir interpretar o motivo de criação dos documentos, e a partir daí fazer os devidos 'cortes' na estrutura do fundo, ou seja, criar os níveis de classificação dentro de fundo. Esses níveis de classificação devem ser escolhidos à partir de um elemento função, estrutura, assunto - e manter a coerência em cada nível hierárquico. Depois de criadas tais subdivisões é necessário codificar e definir a nomenclatura de cada nível de agrupamento documental: seções, classes, subclasses, séries, etc. (SCHELLENBERG, 2006, p. 96).

Desta forma, o processo de construção de planos de classificação precisa ser embasado por levantamento de dados. De acordo com Sousa (2008, p. 134), baseado em Belloto (2004), existem três grupos de dados fundamentais a serem coletados). São eles: dados sobre a organização em seu contexto histórico e social; dados da organização em sua individualidade; dados sobre os documentos produzidos pela organização.

O primeiro conjunto de dados é composto pela lista de datas marcantes, especialmente as de criação e alteração da estrutura organizacional das instituições. São especialmente relevantes para que compreendamos e possamos delimitar o fundo de arquivo, uma vez que a identificação de um fundo documental depende de uma organização funcional precisa. 0 segundo conjunto de dados é referente aquilo que podemos chamar de conceitos do ambiente organizacional: missão, funções, atribuições, atividades e tarefas que a instituição desenvolve. Esses dados são importantes para a escolha dos níveis de classificação do instrumento.

0 terceiro conjunto de dados refere-se aos documentos de arquivo, suas tipologias documentais e sua relação com cada aspecto da organização em sua individualidade: em que setores, departamentos, em quais atividades são produzidos os documentos, quais suas espécies e gêneros documentais. Parece-nos caber as definições de gênero, espécie e tipologia documental, de acordo com o Dicionário Brasileiro de Terminologia Arquivística (ARQUIVO NACIONAL, 2005) e Dicionário de Terminologia Arquivística (ASSOCIAÇÃO DE ARQUIVISTAS BRASILEIROS, 1996). 
Quadro 1: Definições de gênero, espécie e tipologia documental.

\begin{tabular}{|c|l|l|}
\hline \multicolumn{1}{|c|}{ Conceito } & \multicolumn{1}{|c|}{ Definição } & \multicolumn{1}{c|}{ Exemplos } \\
\hline Gênero documental & $\begin{array}{l}\text { Reunião de espécies documentais que se } \\
\text { assemelham por seus caracteres essenciais, } \\
\text { particularmente o suporte e formato que } \\
\text { exigem processamento técnico específico e, } \\
\text { por vezes, mediação técnica para acesso. }\end{array}$ & $\begin{array}{l}\text { Documentos audiovisuais, documentos } \\
\text { bibliográficos, documentos cartográficos, } \\
\text { documentos eletrônicos, documentos } \\
\text { filmográficos, documentos iconográficos, } \\
\text { documentos micrográficos e documentos } \\
\text { textuais. }\end{array}$ \\
\hline Espécie documental & $\begin{array}{l}\text { Divisão de gênero documental que reúne } \\
\text { tipos documentais por seu formato. }\end{array}$ & $\begin{array}{l}\text { Ata, carta, decreto, disco, filme, folheto, } \\
\text { fotografia, memorando, ofício, planta, } \\
\text { relatório, certidão, boletim e declaração. }\end{array}$ \\
\hline Tipologia documental & $\begin{array}{l}\text { Divisão de espécie documental que reúne } \\
\text { documentos por suas características comuns } \\
\text { no que diz respeito à fórmula diplomática, } \\
\text { natureza de conteúdo ou técnica do registro. }\end{array}$ & $\begin{array}{l}\text { Ata de reunião, boletim de ocorrência, } \\
\text { boletim de frequência e rendimento escolar, } \\
\text { certidão de nascimento, certidão de óbito, } \\
\text { declaração de bens, declaração de imposto } \\
\text { de renda, relatório de atividades e relatório } \\
\text { de fiscalização. }\end{array}$ \\
\hline
\end{tabular}

Fonte: Baseado em Arquivo Nacional (2005) e Associação de Arquivistas Brasileiros (1996).

Os planos de classificação arquivísticos devem dar conta de fornecer um lugar coerente para cada tipo documental produzido, guiando através de sua codificação o arquivamento adequado.

Entre as diversas possibilidades de estratégias para a construção de planos de classificação, cita-se a proposta de Rodrigues (2012), que coloca a identificação arquivística como ponto de partida, não apenas para a classificação, mas para a criação de um programa de gestão de documentos (ou seja, da criação até a destinação final dos mesmos). A identificação arquivística consiste em duas fases, semelhante ao proposto por Sousa (2008) mas melhor sistematizado. A primeira parte determina a identificação do órgão produtor através da definição de suas competências, funções e atividades.

Depois dessa primeira sistematização, parte-se para a criação e aplicação de fichas de levantamento de tipologias documentais. (RODRIGUES, 2012). 0 cruzamento desses dados - tipologias documentais e competências, funções e atividades - leva à criação de séries documentais tipológicas, que permitem a vinculação da produção do documento com o órgão produtor de maneira precisa e única, cada qual sendo resultado de um processo da instituição. A autora sugere ainda, como exemplo da implementação da metodologia, a criação de um banco de dados que permita cruzar as informações coletadas automatizando a tarefa de sistematização dos níveis e séries do instrumento.

\section{RESULTADOS}

Definido o fundo documental do OGMO/Rio Grande como ponto de partida, partiu-se para a aplicação da metodologia de identificação arquivística, que consistiu, em sua primeira parte, no estudo do estatuto do órgão, procurando à partir deste documento identificar e sistematizar competências, funções e atividades. Foram ainda coletadas informações do Sistema Geral de Qualidade - SGQ da instituição. Depois disso, foram aplicados Formulários de Identificação de Tipologias Documentais nos setores do OGMO/Rio Grande.

Foi ainda elaborado um banco de dados bastante simples, com dois módulos 
principais. 0 primeiro permitiu registrar todas as funções e suas atividades (Figura 1). 0 segundo módulo permitiu a inserção das informações sobre as tipologias documentais encontradas, que quando inseridas podiam ser relacionadas com determinada atividade já cadastrada, além de diversos outros campos.

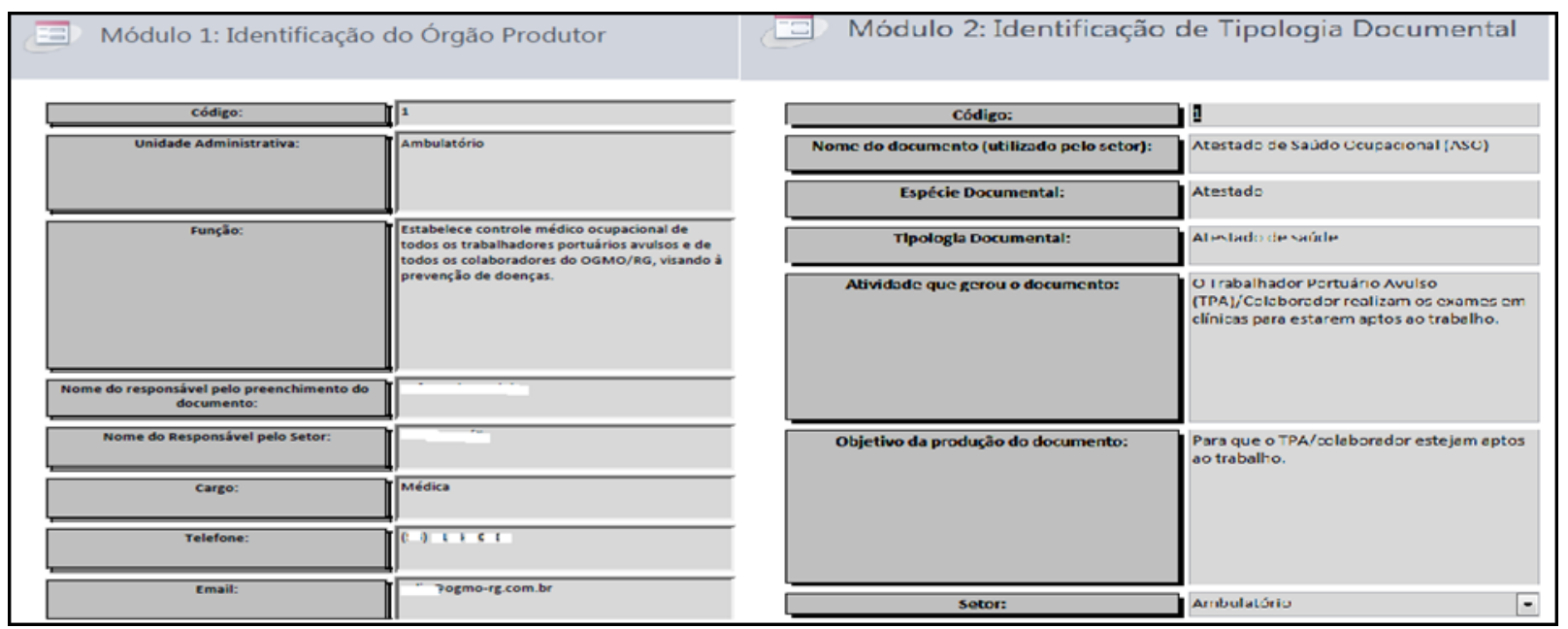

Figura 1: Extrato da tela do banco de dados mostrando os Módulos de inserção e dados Fonte: Dados da pesquisa (2017).

Através da criação de uma consulta no banco de dados, que relacionava funções, atividades e tipologia foi possível sistematizar o plano de classificação, tendo como nível 1 Função, nível 2 Atividade e nível 3 Série (baseada na tipologia documental), conforme extrato apresentado na Figura 2.

\begin{tabular}{|c|c|c|c|c|c|c|}
\hline \multicolumn{7}{|c|}{ FUNDO: OGMO } \\
\hline \multicolumn{2}{|r|}{ FUNIC̄ÃO } & \multicolumn{2}{|r|}{ ATIVIDADE } & \multicolumn{2}{|r|}{ TIPO DÖCUMENTAL (SÉRIE) } & ORDENACĀO \\
\hline 1 & \multirow{17}{*}{$\begin{array}{c}\text { Controle das } \\
\text { atividades de } \\
\text { segurança na serviço } \\
\text { portuário }\end{array}$} & $1-1$ & $\begin{array}{l}\text { Identificação de } \\
\text { atividlades de risco }\end{array}$ & 1-1-1 & Perfil Prafissiográfico Previdenciário & \multirow{17}{*}{$\begin{array}{l}\text { Cronologicamente e por } \\
\text { assunto. }\end{array}$} \\
\hline C & & \multirow[t]{3}{*}{$1-2$} & \multirow{3}{*}{ Controle de segurança } & $1-2-1$ & Lista de presenţa de Diálogos diários de segurança (DDS) & \\
\hline & & & & $1-2-2$ & Lista de presençça de reintegraçăo & \\
\hline & & & & $1-2-3$ & Dossiê do Programa SMS (Gestäø de Segurança) & \\
\hline & & \multirow[t]{3}{*}{$1-3$} & \multirow[t]{3}{*}{ Checagem de segurança } & $1-3-1$ & Listagem de máquinas & \\
\hline & & & & $1-3-2$ & Listagem de barda & \\
\hline & & & & $1-3-3$ & Listagem de capatazia & \\
\hline & & \multirow[t]{4}{*}{$1-4$} & \multirow[t]{4}{*}{ Controle de acidentes } & $1-4-1$ & Ficha de controle de origem de acidentes pessoais & \\
\hline & & & & $1-4-2$ & Ficha de controle de origem de acidentes materiais & \\
\hline & & & & $1-4-3$ & $\begin{array}{l}\text { Dossiê de CPATP (Comissão de prevenção ao acidente aa } \\
\text { Operador Portuário e ao Trabalhardor Portuário Avulso) }\end{array}$ & \\
\hline & & & & $1-4-4$ & Solicitaçâa de comparecimento dio TPA & \\
\hline & & \multirow[t]{3}{*}{$1-5$} & \multirow{3}{*}{$\begin{array}{l}\text { Controle de riscos } \\
\text { ambientais }\end{array}$} & $1-5-1$ & Norma de prewenţăo de riscos ambientais & \\
\hline & & & & $1-5-2$ & Laudo de qualídade da água & \\
\hline & & & & $1-5-3$ & Relatório da Fauna Sinantrópica & \\
\hline & & $1-6$ & Comunicaçö́es diversas & $1-6-1$ & Ofícios enviatos e recebidos & \\
\hline & & $1-7$ & Cargas trabalhadas & $1-7-1$ & Declaraçãa etle manifesto de carga & \\
\hline & & $1-8$ & $\begin{array}{l}\text { Controle de } \\
\text { equipamentos }\end{array}$ & $1-8-1$ & Laudo de equipamentos do Operador Prortuário & \\
\hline \multirow{7}{*}{2} & \multirow{7}{*}{$\begin{array}{c}\text { Compras e distribuiçăo } \\
\text { de materiais }\end{array}$} & \multirow[t]{3}{*}{$2-1$} & \multirow[t]{3}{*}{ Pedidos de material } & $2-1-1$ & Nota fiscal de material & \multirow{7}{*}{$\begin{array}{l}\text { Cronologicamente e por } \\
\text { assunto. }\end{array}$} \\
\hline & & & & $2-1-2$ & Requisiçä̀o de compras & \\
\hline & & & & $2-1-3$ & Solicitaçă de compra de materiais & \\
\hline & & \multirow[t]{3}{*}{$2-2$} & \multirow[t]{3}{*}{ Distribuição de material } & $2-2-1$ & Formulario de EPI's rotativos & \\
\hline & & & & $2-2-2$ & Ficha atiwa de EPl's & \\
\hline & & & & $2-2-3$ & Ficha inativa de $\mathrm{EPI}^{p_{3}}$ & \\
\hline & & $2-3$ & $\begin{array}{l}\text { N.ăo conformidade de } \\
\text { material }\end{array}$ & $2-3-1$ & Notificaçă & \\
\hline
\end{tabular}

Figura 2: Extrato do Plano de Classificação de Documentos do OGMO/Rio Grande Fonte: Dados da pesquisa (2017).

O plano de classificação foi comparado com as instruções técnicas de procedimentos elaborados pelo SGQ, identificando diversos processos que ainda não estavam normatizados. Entre estes setores, o que mais apresentou falta de normatização foi a Secretaria. Tais informações foram transmitidas ao setor de controle 
de qualidade para que possa servir de subsídio para a modelagem de processos mais eficazes.

\section{CONCLUSÕES}

Planos de classificação arquivísticos são complexos porque devem ser construídos de acordo com seu contexto. Nesse sentido, este trabalho demonstra o sucesso da aplicação de uma metodologia, que embora pulverizada na bibliografia, da forma como explicitada por Rodrigues $(2008,2015)$ simplifica o processo de construção tanto pela sistematização da coleta de dados como pelo respeito aos princípios arquivísticos.

Ao mesmo tempo, pode-se utilizar os dados levantados para a estruturação do plano de classificação como recurso para a normatização de procedimentos, encaminhados ao setor de qualidade do OGMO/Rio Grande. Consideramos que a melhoria dos processos se relaciona com o conceito de inovação incremental, demonstrando que a gestão documental pode contribuir com o desenvolvimento das organizações rumo a um melhor desempenho, ainda que muitas vezes tal contribuição não seja diretamente observável pelo usuário dos serviços da mesma.

0 plano de classificação foi aprovado pela entidade e o próximo instrumento de gestão arquivística - a tabela de temporalidade - encontra-se em processo de construção. Compreendemos que a criação do plano de classificação pode ser compreendido como parte de um processo de inovação organizacional, de grau incremental. Isso se dá pelas possibilidades de ampliação do controle e uso dos documentos criados por cada setor. Foi possível estender o conhecimento sobre a produção documental para além dos setores cobertos pelo sistema de qualidade existente. 0 plano de classificação do OGMO/Rio Grande tem potencial, inclusive, de dar início a um programa de gestão de documentos que permita o registro da memória organizacional, e com ela novas possibilidades de criação de inovações nãotecnológicas

\section{REFERÊNCIAS}

ARQUIVO NACIONAL (Brasil). Dicionário Brasileiro de Terminologia Arquivística. Rio de Janeiro: Arquivo Nacional, 2005.

ASSOCIAÇÃO DOS ARQUIVISTAS BRASILEIROS. Dicionário de Terminologia Arquivística. São Paulo, 1996.

BELLOTTO, H. Arquivos permanentes: tratamento documental. Rio de Janeiro: FGV, 2004.

CAMISÓN, C.; LÓPEZ, A. V. Non-technical innovation: Organizational memory and learning capabilities as antecedente factors with effects on sustained competitive advantages. Industrial Marketing Management, v. 40, p. 1294-1304, 2011.

CAPUANO, E. A. Fontes de Informação sobre Conceitos e Indicadores de Inovação. 2015. Disponível em: $<$ https://www.researchgate.net/publication/272415293 Fontes de Informacao sobre Conceito s e Indicadores de_Inovacao>. Acesso em: 18 jan. 2017.

DAMANPOUR, F. Organizational Innovation. Oxford Research Encyclopedia of Business and Management. Disponível em: 
$<$ http://business.oxfordre.com/view/10.1093/acrefore/9780190224851.001.0001/acrefore97 801>. Acesso em: 01 nov. 2017.

FANG, S. H. et al. Relationship learning and innovation: The role of relationship-specific memory. Industrial Marketing Management, v. 40, p. 743-753, 2011.

LEE, W. L. et al. Value creation potential of individual and organizational memory in health care services. Expert Systems with Applications, v. 38, p. 10658-10664, 2011.

LEMOS, C. Inovação na era do conhecimento. In: LASTRES, Helena; ALBAGLI, Sarita (Org.). Informação e globalização na era do conhecimento. Rio de Janeiro: Campus, 1999. p. 122-144.

OCDE. Manual de Oslo. Diretrizes para coleta e interpretação de dados sobre inovação tecnológica. FINEP: [s.l.], 2006.

RODRIGUES, A. C. Identificação arquivística como requisito metodológico do Programa de Gestão de Documentos do Governo do Estado do Rio de Janeiro (PGD-RJ): reflexões sobre a construção teórica dos procedimentos e instrumentos. In: ENCONTRO NACIONAL DE PESQUISA EM CIÊNCIA DA INFORMAÇÃO, 13., 2012, Rio de Janeiro. Anais... Rio de Janeiro, 2012. Disponível em: <http://www.eventosecongressos.com.br/metodo/enancib2012/arearestrita/pdfs/19564.pdf. $>$ Acesso em: 27 mai. 2016.

ROUSSEAU, J-Y.; COUTURE, C. Os fundamentos da disciplina arquivística. Lisboa: Publicações Dom Quixote, 1998.

SCHELLENBERG, T. Arquivos modernos: princípios e técnicas. Rio de Janeiro: FGV, 2006.

SOUSA, R. T. B. de. A classificação como função matricial do que-fazer arquivístico. In: SANTOS, Vanderlei Batista dos (Org.). Arquivística: temas contemporâneos. 2. ed. Distrito Federal: Senac, 2008. p. 78-172.

TIRONI, L. F.; CRUZ, B. de O. Inovação incremental ou radical: há motivos para diferenciar? Uma abordagem com dados da Pintec. 2008. IPEA - Texto para discussão no 1360 . Disponível em: <http://repositorio.ipea.gov.br/bitstream/11058/1537/1/TD_1360.pdf >. Acesso em: 27 mar. 2017. 